\title{
Managing Customers' Satisfaction: Evidence from Mining User Generated Content on the Internet
}

\author{
Susan (Sixue) $\mathrm{Jia}^{1}$ \\ ${ }^{1}$ School of Business and Management, Shanghai International Studies University, Shanghai, China \\ Correspondence: Susan (Sixue) Jia, School of Business and Management, Shanghai International Studies University, \\ Shanghai, 200083, China. Tel: 86-21-3537-2500. E-mail: s.jia@ shisu.edu.cn
}

Received: October 1, 2017

Accepted: October 15, 2018

Online Published: October 17, 2018

doi:10.5430/bmr.v7n4p1

URL: https://doi.org/10.5430/bmr.v7n4p1

\begin{abstract}
Establishing the connection between online ratings and reviews is a cost effective approach for karaoke managers to detect customer satisfaction. For this purpose, this study uses a combined approach that incorporates text mining and empirical modeling to quantitatively investigate user generated content on the internet. From Dianping.com, the largest crowd-sourced online review community of China, 47,069 pieces of karaoke rating and review were screened, with major topics identified. Multilinear regression was conducted to uncover the most impactful factors that influence overall, environment, sound effect, and service ratings. Managerially, the idea of triggering the synergistic benefit from customer ratings and reviews is referential for market practitioners both within and beyond the karaoke industry.
\end{abstract}

Keywords: karaoke, online rating, online review, text mining

\section{Introduction}

Karaoke is an interactive entertainment in which a singer sings along with a music video using a microphone. Typically, the music is an instrumental version of a popular song, whereas its lyrics are usually displayed on the bottom of the screen. Karaoke operators have been making great effort in improving karaoke customer experience from a technical perspective, e.g., evaluating singing performances (Tsai \& Lee, 2012), precisely recommending songs (Guan et al. 2017), facilitating multiparty karaoke over the internet (Wang, Pan, Feng, \& Deng, 2012), querying for song by singing or humming (Song, Park, Yang, Jang, \& Lee, 2013), or personalising the system (Hua, Lu, \& Zhang, 2004). However, less attention has been paid to enhance customer satisfaction from a service perspective, which is actually equally or even more important than its technical counterpart, e.g., creating a pleasant physical environment (Wu, Hua, \& Chen, 2015), training employees (Wu et al. 2015), responding to consumers complaints (Lo, Wei, Lu, \& Ko, 2016), and motivating social bonding (Fung, 2009).

Karaoke customers have been posting online ratings and online reviews to narrate, praise, or criticise their karaoke experiences. Such user generated content (UGC) is a valuable information source from which karaoke managers can capture satisfaction and quality improvement hints. Online rating and review are two typical forms of UGC (Ye, Law, Gu, \& Chen, 2011; Bilgihan, Seo, \& Choi, 2017). Rating usually takes the form of a five-point scale. It quantitatively shows whether and to what extent a consumer is satisfied with the product or service (Anderson \& Magruder, 2012). Review is a piece of written comment. It depicts the experience of the customer with the product or service in a qualitative style (Lee \& Bradlow, 2011). Examined together, rating and review can create a complete description of consumer satisfaction and can synergistically enhance research effectiveness (Büschken \& Allenby, 2016; Hao, Zhang, Wang, \& Gao, 2017).

Based on the above background and research gap, this study aims at detecting karaoke customers' satisfaction by mining UGC on the Internet. More specifically, this paper unfolds as follows. The "method" section describes the source of karaoke UGC, as well as the acquisition, processing, and analysis of these data using statistical and text mining tools. Subsequently, the "results and discussions" section reports the findings from the data, and further interprets the findings with methodological and managerial implications. Finally, the "conclusions" section summarises the whole paper by revisiting the key issues of this study and providing future study suggestions.

Methodologically, this study contributes by proposing a standard procedure of connecting the quantitative and 
qualitative online data. Meanwhile, this paper also identifies the most influential factors that affect karaoke consumer satisfaction and provides practical managerial implications.

\section{Method}

\subsection{Data Source}

From Dianping.com, the largest crowd-sourced online review community of China, 100 karaoke sites in Shanghai, China were randomly chosen. Existing researches support the idea of focusing on specific geographic areas to control the spatial, historical, and cultural factors (Ginsberg, 2000; Andreasson \& Johansson, 2015; Öner \& Klaesson, 2017). All the selected karaoke sites have at least 100 pieces of rating and review created by its consumer during 2006-2017, ensuring that the findings obtained from these sites are statistically reliable.

A typical karaoke customer leaves the following UGC on a karaoke site: (1) overall rating, a five-point scale ("5ps" for short), (2) environment rating (5ps), which assesses the infrastructure and atmosphere, (3) sound effect rating $(5 \mathrm{ps})$, which assesses the microphone and sound box, (4) service rating $(5 \mathrm{ps})$, which assesses the regular service and supporting staff, and (5) review comments.

\subsection{Review Topic Identification}

Latent Dirichlet allocation (LDA) method is employed to detect topic. The method uses probabilistic topic model (Blei, Ng, \& Jordan, 2003; Blei 2012), which assumes the word generation in a document as a two-stage process:

(1) Randomly select a distribution of topics.

(2) For each word in the document,

(a) Randomly select a topic from the distribution of topics in (1).

(b) Randomly select a word from the distribution of the vocabulary.

In real conditions, neither the distribution of topics over documents nor the distribution of words over topics is known in the first place; only the documents are explicitly given. The relation between latent and explicit parameters is the co-distribution expressed using Equation (1).

$$
p\left(\beta_{1: K}, \theta_{1: D}, z_{1: D}, w_{1: D}\right)=\prod_{i=1}^{K} p\left(\beta_{i}\right) \cdot \prod_{d=1}^{D} p\left(\theta_{d}\right) \cdot \sum_{n=1}^{N} p\left(z_{d, n} \mid \theta_{d}\right) p\left(w_{d, n} \mid \beta_{1: K}, z_{d, n}\right)
$$

$\beta_{i} \quad$ distribution of word in topic $i$, altogether $K$ topics

$\theta_{d} \quad$ proportions of topics in document $d$, altogether $D$ documents

$z_{d} \quad$ topic assignment in document $d$

$z_{d, n} \quad$ topic assignment for the $n^{\text {th }}$ word in document $d$, altogether $N$ words

$w_{d} \quad$ observed words for document $d$

$w_{d, n} \quad$ the $n^{\text {th }}$ word for document $d$

The identification of topics and words is thus a posteriori estimation (Equation 2) using Gibbs sampling (Griffiths \& Steyvers, 2004). In this study, the estimation was computed by Python LDA 1.0.5 (The Python Community, 2017a), whereas Python Jieba 0.39 (The Python Community, 2017b) was used to process the Chinese language.

$$
p\left(\beta_{1: K}, \theta_{1: D}, z_{1: D} \mid w_{1: D}\right)=\frac{p\left(\beta_{1: K}, \theta_{1: D}, z_{1: D}, w_{1: D}\right)}{p\left(w_{1: D}\right)}
$$

\subsection{Rating-Review Modelling}

The above LDA-based text mining helps identify the topics that karaoke customers most care about regarding their karaoke experience. However, text mining alone does not tell how these topics are associated with attitude or satisfaction. Therefore, it is necessary to establish the relation between review and rating, creating a bridge that links the factual data (i.e., reviews) with attitudinal data (i.e., ratings).

For this purpose, multilinear regression model was applied to estimate the rating-review relation (Büschken \& Allenby, 2016; Jia, 2018a). Moreover, because treating the words in one topic together as a single factor results in coarse grain clusters and thus limited managerial insights (Büschken \& Allenby, 2016; Jia, 2018b), the topics were manually broken and reorganised into smaller word groups, with each group representing one fine grain factor. 
Equation (3) is the model regarding overall (OV) rating, whereas environment (EN), sound effect (SO), and service (SV) adopt similar ones.

$$
\operatorname{RATING}^{O V}=\beta_{0}^{O V}+\sum_{i=1}^{N} \beta_{i}^{O V} \times W O F_{i}+\varepsilon
$$

$R A T I N G^{\text {OV }}$ Overall rating for a review

$\beta_{0}^{O V} \quad$ Intercept of the model

$N \quad$ Total number of factors

$\beta_{i}^{O V} \quad$ Coefficient for the $i^{\text {th }}$ factor for overall rating

$W O F_{i} \quad$ Weight of the $i^{\text {th }}$ factor in the review, calculated by Equation (4)

$$
W O F_{i}=\frac{f_{i}}{\sum_{j} f_{j}}
$$

$f_{i} \quad$ Number of times a word in the review is allocated to factor $i$

$\sum_{j} f_{j} \quad$ Number of words in the review that are allocated to a factor

\section{Results}

\subsection{Descriptive Statistics}

A total of 47069 pairs of rating and review were obtained from Dianping.com, commenting on the 100 karaoke sites in Shanghai, China. The distributions of UGC over ratings have been summarised in Figure 1. The distributions for overall, environment, sound effect, and service ratings are similar, with nearly half of the users assigning 5 star, nearly another quarter of users giving 4 star, an eighth of them assigning 3 star, and the rest giving 2 or 1 star. The existence of a significant fraction of lower ratings (i.e., 2 or 1 star) provides the opportunity to explore the reasons why karaoke customers are unsatisfied, from which subsequent managerial implications can be drawn.

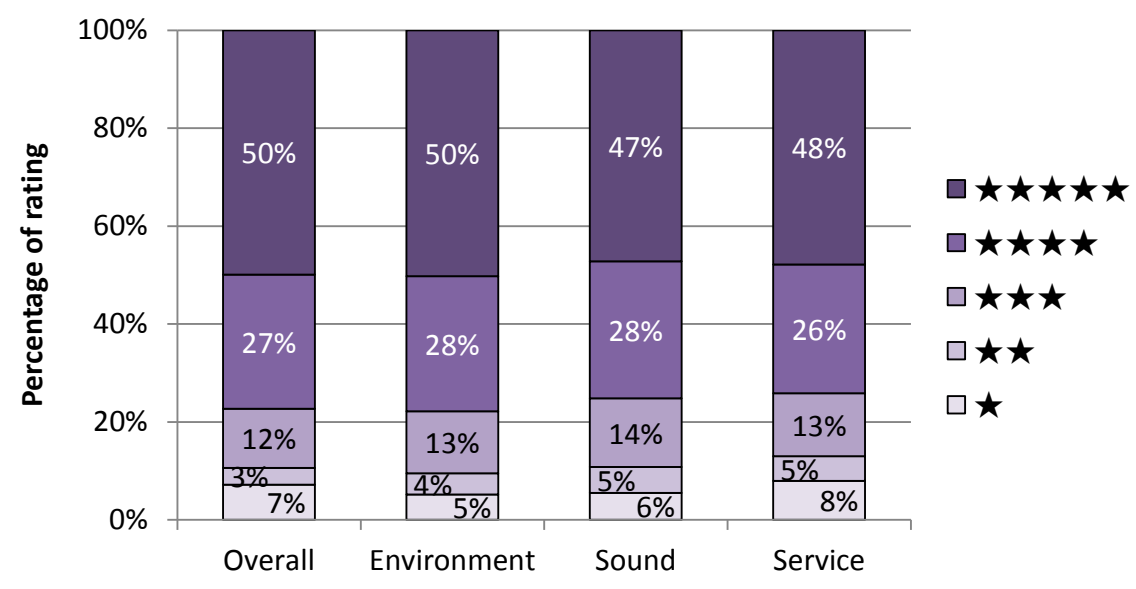

\subsection{Topics in Review}

Figure 1. Distributions of UGC over Ratings

From the reviews written by the karaoke customers, 13 topics were successfully extracted using LDA. These topics were further classified into 5 categories, as are shown in Table 1. The first topic category is the occasion of karaoke consumption. Although people may come to a karaoke for different purposes, the data suggests that more of them are there to hold parties for kids or colleagues. Therefore, karaoke operators are encouraged to targetedly prepare for these occasions, e.g., children's food, designated drivers, et al. 
Table 1. Topics identified using LDA

\begin{tabular}{|c|c|c|c|c|c|c|}
\hline Category & Topic & Word & & & & \\
\hline \multirow[t]{4}{*}{ Occasion } & Kid party & happiness & friend & play & fun & birthday \\
\hline & & joyful & kid & enjoy & child & party \\
\hline & Colleague party & party & friend & place & suitable & colleague \\
\hline & & company & environment & entertain & relax & first choice \\
\hline \multirow[t]{6}{*}{ Environment } & Location & elevator & traffic & place & location & find \\
\hline & & subway & geographic & road & parking & mall \\
\hline & Environment & environment & room & clean & compartment & air conditioning \\
\hline & & fitment & restroom & cigarette smell & sofa & lighting \\
\hline & Compartment & small compartment & middle compartment & large compartment & theme & book \\
\hline & & spacious & decoration & screen & comfortable & standing microphone \\
\hline \multirow[t]{6}{*}{ Effect } & VOD system & song ordering & microphone & VOD system & cellphone & song \\
\hline & & rating & screen & audio & broken & repertoire \\
\hline & Repertoire & song ordering & song & repertoire & new song & latest \\
\hline & & old song & complete & find & list & musician \\
\hline & Sound quality & effect & sound quality & sound proof & sound & microphone \\
\hline & & quality & room & interfere & nextdoor & sound box \\
\hline \multirow[t]{6}{*}{ Service } & Reservation & reservation & ahead & groupon & phone & time \\
\hline & & hour & compartment & front desk & online & queue \\
\hline & Waiter & service & waiter & service attitude & hospitable & front desk \\
\hline & & bell & satisfied & praise & help & active \\
\hline & Food & drink & supermarket & beverage & bear & snack \\
\hline & & wine & fruit & popcorn & price & bottle \\
\hline \multirow[t]{4}{*}{ Price } & Price & hour & groupon & RMB & cheap & afternoon \\
\hline & & coupon & cost performance & weekday & evening & price \\
\hline & Membership & buffet & free & coupon & RMB & membership card \\
\hline & & register & birthday & membership & hour & discount \\
\hline
\end{tabular}

The second topic category is environment, including location, physical environment, and compartment. A karaoke customer judges the environment of a karaoke site even before he/she arrives by accessing the convenience of traffic, e.g., subway, parking, et al. Afterwards, the customer perceives the physical environment, involving cleanness, temperature, lighting, et al. Finally, the customer spends most time in a compartment, be it small, middle, or large.

The third topic category is effect, involving the voice-on-demand (VOD) system, the repertoire, and the sound quality. The VOD system is an interface that interacts with the customer and facilitates song selection. A good system responds quickly and is easy to use. The repertoire refers to the full collection of songs stored in the system. Some customers are fond of older songs, while others may prefer the latest release. No matter which song, sound quality is of critical importance, considering both intra-room sound effect and inter-room sound proof.

The fourth topic category is service, incorporating reservation service, waiter service, and food service. Karaoke sites face the dilemma of maximising potential customers' satisfaction as well as optimised resource allocation when handling a reservation request. Of greater important is the waiter service, which starts from compartment setup, 
followed by immediate service call, and ends with checkout. Meanwhile, food, as a complimentary or value-added service, is also frequently mentioned in karaoke UGC.

The final topic category is price, including general price and membership. The general price topic focuses on cost performance, as well as the variation of cost with consumption time, e.g., afternoon, weekday, et al. The membership topic involves registering membership in return for discount or free hours.

As is previously discussed, because treating the words in one topic together as a single factor results in coarse grain clusters (such as compartment) and thus limited managerial insights, the topics were manually broken and reorganised into smaller word groups, with each group representing one fine grain factor, see Table 2.

Table 2. Potentially influential factors

\begin{tabular}{lcccccc}
\hline Factor & air conditioning & birthday & cigarette smell & colleague & compartment & cost performance \\
\hline Abbr. & $A C$ & BDAY & CIGAR & COLLG & COMPT & CSTPF \\
\hline Factor & decoration & drink & fitment & front desk & groupon & GROUP \\
\hline Abbr. & DECOR & DRINK & FITMT & FDESK & new song & LCOMP \\
\hline Factor & lighting & membership card & microphone & middle compartment & NSONG & OSONG \\
\hline Abbr. & LIGHT & MEMBR & MIC & MCOMP & restroom & service attitude \\
\hline Factor & parking & price & repertoire & reservation & RROOM & SRVAT \\
\hline Abbr. & PARK & PRICE & REPTR & RESRV & standing microphone & VOD system \\
\hline Factor & small compartment & sofa & sound proof & sound quality & STDMC & SQUAL
\end{tabular}

3.3 Rating-review relation

Multilinear regression was applied to estimate the rating-review relation, with the result summarised in Table 3. Notice that one of the factors, MCOMP, is removed from the model to avoid multicollinearity. In Table 3, negative coefficients indicate that if the corresponding factor is mentioned in the review (compared with not-mentioned), the corresponding rating is likely to be lower. In other words, the factor (e.g., front desk) is to be improved. On the contrary, positive coefficients (e.g., decoration) indicate the karaoke sites have good performance in the corresponding aspects. 
Table 3. Regression result for rating-review relations

\begin{tabular}{|c|c|c|c|c|c|c|c|c|}
\hline \multirow{2}{*}{$\begin{array}{c}\text { Abbr. } \\
D E C O R\end{array}$} & \multicolumn{2}{|c|}{ OV } & \multicolumn{2}{|l|}{$\mathbf{E N}$} & \multicolumn{2}{|l|}{ SO } & \multicolumn{2}{|l|}{ SV } \\
\hline & 0.595 & $* * *$ & 0.556 & $* * *$ & 0.499 & $* * *$ & 0.501 & $* * *$ \\
\hline CSTPF & 0.581 & $* * *$ & 0.408 & $* * *$ & 0.396 & $* * *$ & 0.528 & $* * *$ \\
\hline$C O L L G$ & 0.546 & $* * *$ & 0.444 & $* * *$ & 0.435 & $* * *$ & 0.456 & $* * *$ \\
\hline$S Q U A L$ & 0.531 & $* * *$ & 0.443 & $* * *$ & 0.388 & $* * *$ & 0.534 & $* * *$ \\
\hline$B D A Y$ & 0.512 & $* * *$ & 0.421 & $* * *$ & 0.415 & $* * *$ & 0.503 & $* * *$ \\
\hline PARK & 0.424 & $* * *$ & 0.330 & $* *$ & 0.342 & $* *$ & 0.457 & $* * *$ \\
\hline PRICE & 0.337 & $* * *$ & 0.210 & $* * *$ & 0.199 & $* *$ & 0.281 & $* * *$ \\
\hline FITMT & 0.288 & $* * *$ & 0.130 & $*$ & 0.141 & $*$ & 0.248 & $* * *$ \\
\hline REPTR & 0.288 & $* * *$ & 0.231 & $* * *$ & 0.129 & $*$ & 0.281 & $* * *$ \\
\hline$N S O N G$ & 0.255 & $* *$ & 0.149 & & 0.139 & & 0.354 & $* * *$ \\
\hline$L I G H T$ & 0.254 & * & 0.080 & & 0.176 & & 0.182 & \\
\hline STDMC & 0.238 & & 0.248 & & 0.208 & & 0.206 & \\
\hline OSONG & 0.166 & & 0.015 & & -0.137 & & 0.112 & \\
\hline$S R V A T$ & 0.164 & $* *$ & 0.164 & $* *$ & 0.171 & $* *$ & 0.092 & \\
\hline GROUP & 0.081 & & 0.017 & & 0.024 & & 0.008 & \\
\hline МСOМР & - & & - & & - & & - & \\
\hline$S D P R F$ & 0.059 & & -0.052 & & -0.187 & $*$ & 0.107 & \\
\hline$S C O M P$ & -0.048 & & -0.073 & & -0.097 & & -0.094 & \\
\hline$C O M P T$ & -0.118 & & -0.132 & $*$ & -0.117 & & -0.161 & $*$ \\
\hline$L C O M P$ & -0.136 & & -0.178 & $*$ & -0.130 & & -0.260 & $* *$ \\
\hline$V O D$ & -0.252 & $* * *$ & -0.265 & $* * *$ & -0.377 & $* * *$ & -0.112 & \\
\hline$M E M B R$ & -0.266 & $*$ & -0.225 & $*$ & -0.295 & $* *$ & -0.393 & $* * *$ \\
\hline DRINK & -0.290 & $* * *$ & -0.266 & $* *$ & -0.208 & $*$ & -0.449 & $* * *$ \\
\hline RROOM & -0.325 & $* * *$ & -0.542 & $* * *$ & -0.342 & $* * *$ & -0.330 & $* * *$ \\
\hline$M I C$ & -0.481 & $* * *$ & -0.444 & $* * *$ & -0.768 & $* * *$ & -0.478 & $* * *$ \\
\hline$C I G A R$ & -0.541 & $* * *$ & -1.055 & $* * *$ & -0.385 & $* * *$ & -0.407 & $* * *$ \\
\hline$R E S R V$ & -0.685 & $* * *$ & -0.554 & $* * *$ & -0.575 & $* * *$ & -0.754 & $* * *$ \\
\hline$A C$ & -0.741 & $* * *$ & -0.988 & $* * *$ & -0.668 & $* * *$ & -0.724 & $* * *$ \\
\hline SOFA & -0.748 & $* * *$ & -1.055 & $* * *$ & -0.732 & $* * *$ & -0.733 & $* * *$ \\
\hline FDESK & -1.495 & $* * *$ & -1.149 & $* * *$ & -1.139 & $* * *$ & -1.841 & $* * *$ \\
\hline Constant & 3.957 & $* * *$ & 4.063 & $* * *$ & 4.001 & $* * *$ & 3.919 & $* * *$ \\
\hline
\end{tabular}

$* \mathrm{p}<0.01, * * \mathrm{p}<0.005, * * * \mathrm{p}<0.001$

According to Table 3, karaoke customers have been relatively satisfied with several of the factors, e.g., elaborate fitment and decoration, reasonable price or cost performance, suitability for colleague or birthday party, excellent sound quality, sound quality, convenience of parking, as well as well-maintained repertoire. In other words, karaoke operators may put less money or effort in further improving these factors in the near future. 
On the other hand, Table 3 also reveals the factors that karaoke customers have been quiet unsatisfied with, including unhelpful front desk or reservation staff, uncomfortable sofa or air conditioning, cigarette smell (perhaps) in restroom, poor microphone, bad drink, or less beneficial membership card. Karaoke managers are strongly encouraged to focus on the improvement of these factors to lessen customer complaints.

\section{Conclusion}

Discovering the business value of karaoke consumers' online UGC requires studying rating and review together. This paper bridges the gap between rating and review data and established their connections, which adds value to the tool kit of business research. The online review was analysed with LDA to detect topics. Quantified with weight of factor, the review data was then correlated to rating values by means of multilinear regression. Finally, the relative influence of each factor on karaoke consumers' satisfaction was compared by examining the estimated coefficients.

Despite these achievements, this study is not without limitations. On one hand, the analysis of data incorporates human knowledge, which more or less involves arbitrariness. To be more specific, the naming of topic and the selection of influential factors both require the researcher to improvise or decide. Future studies may consider further reduce the fraction of human involvement in the text mining process, so as to generate a more generalised and standardised protocol of knowledge discovery.

On the other hand, the data of this study may contain bias, because all the data points we collected were karaoke consumers who have assigned ratings and reviews online. Hence, we might have ignored those consumers who were less active on the internet. To put it another way, we are not absolutely sure that the studied karaoke consumers can represent all the consumers. To further increase the reliability of our findings, we suggest future studies leverage both text mining and traditional offline approaches to eliminate the sample bias.

\section{References}

Anderson, M., \& Magruder, J. (2012). Learning from the crowd: Regression discontinuity estimates of the effects of an online review database. The Economic Journal, 122, 957-989. https://doi.org/10.1111/j.1468-0297.2012.02512.x

Andreasson, J., \& Johansson, T. (2015) The new fitness geography: The globalisation of Japanese gym and fitness culture. Leisure Studies, 36, 383-394. https://doi.org/10.1080/02614367.2015.1105858

Büschken, J., \& Allenby, G. M. (2016). Sentence-based text analysis for customer reviews. Marketing Science, 35, 953-975. https://doi.org/10.1287/mksc.2016.0993

Bilgihan, A., Seo, S., \& Choi, J. (2017). Identifying restaurant satisfiers and dissatisfiers: Suggestions from online reviews. Journal of Hospitality Marketing \& Management, 27(5), 601-625. https://doi.org/10.1080/19368623.2018.1396275

Blei, D. M., Ng, A. Y., \& Jordan, M. I. (2003). Latent Dirichlet allocation. Journal of Machine Learning Research, 3, 993-1022. https://doi.org/10.1162/jmlr.2003.3.4-5.993

Blei, D. M. (2012). Probabilistic topic models. Communications of the ACM, 55, 77-84. https://doi.org/10.1145/2133806.2133826

Fung, A. (2009). Consuming karaoke in China modernities and cultural contradiction. Chinese Sociology \& Anthropology, 42, 39-55. https://doi.org/10.2753/CSA0009-4625420202

Ginsberg, L. (2000) The hard work of working out: Defining leisure, health, and beauty in a Japanese fitness club. Journal of Sport \& Social Issues, 24(3), 260-281. https://doi.org/10.1177/0193723500243004

Griffiths, T. L., \& Steyvers, M. (2004). Finding scientific topics. Proceedings of the National Academy of Science, 101, 5228-5235. https://doi.org/10.1073/pnas.0307752101

Guan, C., Fu, Y. J., Lu, X. J., Chen, E. H., Li, X. L., \& Xiong, H. (2017). Efficient karaoke song recommendation via multiple kernel learning approximation. Neurocomputing, 254, 22-32. https://doi.org/10.1016/j.neucom.2016.10.083

Hao, H., Zhang, K., Wang, W., \& Gao, G. (2017). A tale of two countries: International comparison of online doctor reviews between China and the United States. International Journal of Medical Informatics, 99, 37-44. https://doi.org/10.1016/j.jimedinf.2016.12.007

Hua, X. -S., Lu, L., \& Zhang, H, -J. (2004). P-Karaoke: Personalized Karaoke system. In Proceedings of the 12th ACM International Conference on Multimedia, New York, NY, October 10, 2004-October 16, 2004. 
https://doi.org/10.1145/1027527.1027563

Jia, S. (2018a). Behind the ratings: Text mining of restaurant customers' online reviews. International Journal of Market Research, forthcoming. https://doi.org/10.1177/1470785317752048

Jia, S. (2018b). Toward a better fitness club: Evidence from exerciser online rating and review using latent Dirichlet allocation and support vector machine. International Journal of Market Research, forthcoming. https://doi.org/10.1177/1470785318770571

Lee, T. Y., \& Bradlow, E. T. (2011). Automated marketing research using online customer reviews. Journal of Marketing Research, 48, 881-894. https://doi.org/10.1509/jmkr.48.5.881

Lo, T. S, Wei, H. L., Lu, H. P., \& Ko, H. T. (2016). Integrating the Kano model with NSD and EMF to assess the innovative attributes of service quality: An empirical study of Taiwan's KTV service industry. Quality Technology \& Quantitative Management, 13, 416-438. https://doi.org/10.1080/16843703.2016.1191154

Öner, Ö., \& Klaesson, J. (2017) Location of leisure: The new economic geography of leisure services. Leisure Studies, 36(2), 203-219. https://doi.org/10.1080/02614367.2016.1246588

The Python Community. (2017a). LDA 1.0.5: Topic modeling with latent Dirichlet allocation. Available online: https://pypi.python.org/pypi/lda/ (accessed on 15 Oct 2018).

The Python Community. (2017b). Jieba 0.39: Chinese words segmentation utilities. Available online: https://pypi.python.org/pypi/jieba/ (accessed on 15 Oct 2018).

Song, C. J., Park, H., Yang, C. M., Jang, S. J., \& Lee, S. P. (2013). Implementation of a practical query-by-singing/humming system and its commercial applications. IEEE Transactions on Consumer Electronics, 59, 407-414. https://doi.org/10.1109/ICCE.2013.6486813

Tsai, W. H, \& Lee, H. C. (2012). Automatic evaluation of karaoke singing based on pitch, volume, and rhythm features. IEEE Transactions on Audio Speech \& Language Processing, 20, 1233-1243. https://doi.org/10.1109/TASL.2011.2174224

Wang, J. H., Pan, J. Y., Feng, S. C., \& Deng, D. J. (2012). Enabling multiparty karaoke over Internet based on low-level computers: Practice and experiment. International Journal of Communication Systems, 25, 1015-1033. https://doi.org/10.1002/dac.1302

Wu, S. H., Huang, C. T., \& Chen, Y. F. (2015). Leisure-service quality and hedonic experiences: Singing at a karaoke house as a form of theatre. Total Quality Management \& Business Excellence, 26, 298-311. https://doi.org/10.1080/14783363.2013.814290

Ye, Q., Law, R., Gu, B., \& Chen, W. (2011). The influence of user-generated content on traveler behavior: An empirical investigation on the effects of e-word-of-mouth to hotel online bookings. Computers in Human Behavior, 27, 634-639. https://doi.org/10.1016/j.chb.2010.04.014 